\title{
Reflexión y análisis de políticas y prácticas innovadoras a la luz de las representaciones sociales y de la necesidad de una educación intercultural en la formación inicial docente*
}

\author{
Reflection and analysis of innovative policies and practices \\ through the social representations and the need of intercultural education \\ as part of the initial teacher training process
}

\section{Reflexão e análise das políticas e práticas inovadoras, à luz das representações sociais e da necessidade de uma educação intercultural na formação inicial de professores}

\author{
Virginia Aranda \\ Universidad Metropolitana de Ciencias de la Educación \\ Teléfono (56-2) 2412487. E-mail: virginia.aranda@umce.cl
}

\begin{abstract}
RESUMEN
La exclusión social y cultural es uno de los principales fenómenos que tensionan las relaciones de una sociedad, que define sus prioridades educacionales en un marco regulador de base neoliberal, con la formación de estudiantes de pedagogía, que requieren incorporar a su marco valórico ideales democráticos y de respeto mutuo. Considerada esta falencia como una fractura de la relación educación, sociedad, migraciones recientes y pueblos originarios, se requiere abordar críticamente las prácticas pedagógicas de formación inicial docente para el desarrollo de la integración cultural como valor deseable, basando sus innovaciones en estudios, investigaciones y análisis de las políticas educacionales en este ámbito.

A partir de los aportes teóricos recogidos en exploraciones previas, reflexionamos sobre la responsabilidad de la Formación Inicial Docente, sobre temas de investigación y formación en y para una praxis innovadora de curriculum intercultural, que aborden las representaciones racistas y xenófobas de nuestros estudiantes de pedagogía, y que posteriormente les permiten formar a los escolares del sistema para la convivencia democrática, la acogida y el respeto mutuo.
\end{abstract}

Palabras clave: representaciones sociales, racismo, xenofobia, educación intercultural.

\begin{abstract}
Social and cultural exclusion are some of the main issues that affect relationships within a society which defines its educational priorities inside a neoliberal regulatory framework, as seen in the situation of pedagogical training students who need to incorporate in their democratic frameworks values of mutual respect. This issue is considered a key tension point in the relationship between education, society, recent migrations and indigenous people; thus, it makes it necessary to tackle critically the pedagogical practices in initial teacher training, for the development of cultural integration as a desirable value, basing its innovations in studies, research and analysis of educational policies.

From theoretical contribution collected from previous research work, we reflect on the responsibility of the Initial Teacher Training Process, research and forming themes of and for innovate practices of the intercultural curriculum, which include the racists and xenophobic representations of our pedagogy students, and which, eventually, will allow them to teach differently to the students of our national system, stimulating democratic life, acceptance and mutual respect.
\end{abstract}

Key words: social representations, racism, xenophobia, intercultural education.

* $\quad$ Auspiciado por DIUMCE, fondo APIS 2010. 


\begin{abstract}
RESUMO
A exclusão social e cultural é um dos maiores fenômenos que colocam em crises as relações de uma sociedade, que define suas prioridades educacionais em um quadro regulamentar com base neoliberal. A formação dos futuros professores exige incorporar em seu quadro de valores os ideais democráticos de respeito mútuo. Se considerada dita falha como fratura da relação entre educação, sociedade, migração recente e povos indígenas. Precisa-se um olhar critico das práticas pedagógicas de formação inicial de professores para o desenvolvimento da integração cultural como um valor desejável, visando suas inovações em educação na pesquisa e análise da política educacional nesta área.

Em contribuições teóricas coletadas em pesquisas anteriores, refletimos sobre a responsabilidade da formação inicial de professores sobre questões da formação em e para uma prática inovadora do currículo intercultural, que considere as representações racistas e xenófobas de nossos estudantes de pedagogia, visando permitir-lhes a formação dum sistema de convivência democrática da escola, de aceitação e respeito mútuo.
\end{abstract}

Palavras chaves: representações sociais, racismo, xenofobia, educação intercultural.

\title{
1. CONTEXTO
}

Los problemas asociados a dinámicas de cambio cultural que devienen de la globalización actual en las sociedades latinoamericanas implican nuevas maneras de formar a los futuros educadores, que deben basarse en la investigación sobre lo inter y multicultural de la sociedad y los procesos de socialización y educación en un contexto de inmigraciones crecientes.

Los temas en que hemos venido trabajando son un continuum, desde la mirada cualitativa, en la que se imbrican representaciones socioculturales, prejuicios xenófobos y racistas, los que a su vez forman parte del sentido común de la cultura de la que provenimos y, como tales, subyacen en la formación pedagógica que no asume ni explicita estos aspectos. Nuestra búsqueda se ha desarrollado en torno a los temas de las representaciones racistas o xenófobas presentes en los que serán en un futuro próximo profesores/as y su impacto en las poblaciones de niños y niñas inmigrantes o pertenecientes a cualquier minoría étnica o de otro tipo.

Para investigar este fenómeno nos hemos preguntado por sus significados y por los actores que involucra. Sin embargo, complementariamente a los análisis históricos de la exclusión y mestizaje en Chile (Cañulef, E., 1998), siguiendo lo planteado por Ramonet (1999) parece fundamental considerar también el papel que juegan las migraciones contemporáneas en las nuevas dinámicas sociales, así como la incidencia de los actores de la globalización, los papeles que juegan y su influencia en los cambios que inevitablemente ha comenzado a vivir la educación en nuestro país, considerando que las migraciones son estratégicas en las transformaciones sociales contemporáneas. Por una parte, son el resultado del cambio global (Castles, 2002), pero por otra, son una fuerza poderosa de cambios tanto en las sociedades de origen como en las receptoras. Los primeros impactos son los económicos, pero evidentemente no son los únicos. Los cambios en las relaciones sociales, la cultura, la política nacional y las relaciones internacionales, son algunos de los efectos que podemos esperar.

El asentamiento de los inmigrantes puede transformar la economía nacional y las ciudades y necesitan reflexión individual y colectiva sobre los valores sociales y culturales. Una manera, es a través del estudio de las representaciones sociales en el sentido común y la formación educacional, particularmente en la pedagogía, porque los futuros profesores y el mismo profesorado no están exentos de representaciones de distinto tipo, las que se han formado a lo largo de su historia de vida y como parte de su socialización y el imaginario cultural al que pertenecen. 
En esta perspectiva estudiamos las representaciones xenófobas y racistas que forman parte de dicho imaginario colectivo al que pertenecen estos futuros profesionales, para ofrecer recursos pedagógicos de afrontamiento de esta realidad.

En este proceso de formación y desde esta nueva mirada, se espera que el estudiante tome conciencia de su experiencia de vida y su relación directa con los agentes de socialización escolar, y de las teorías interculturales implícitas y explícitas que subyacen en las prácticas docentes. Esta revisión establece las representaciones configuradas como paradigma educativo dominante para promover una aceptación consciente de las nuevas competencias, con las cuales el futuro docente debe asumir los cambios que se impulsan en la Reforma Educacional del país y las nuevas políticas de integración cultural, con recursos propios. Por nombrar algunos: competencias en la comunicación intercultural, posibles consecuencias de los prejuicios y estereotipos sobre grupos de minorías, saberes y herramientas para tratar con la diversidad.

Para avanzar en estos temas, nos hemos planteados dos objetivos transversales orientadores de nuestra línea de investigación en la UMCE, que se basan en dos investigaciones vinculadas a la DIUMCE ${ }^{1}$ :

- Contribuir a la comprensión y análisis de las representaciones simbólicas en torno a las cuales se configuran actitudes y pensamientos racistas y xenófobos en y con estudiantes de pedagogía de la UMCE.

- Desarrollar estrategias curriculares innovadoras que incorporen la Educación Intercultural a la Formación Docente Inicial.

\subsection{BASES TEÓRICAS}

En una primera investigación, definimos la representación como un resultado no intencionado en el aprendizaje que genera una construcción cognitiva, emotiva, volitiva y simbólica. Constituida por elementos objetivos y subjetivos, tales como imágenes, ideas y creencias propias del sentido común que están cargadas de sentimientos y emociones que condicionan el significado que se tenga; por ejemplo, de estereotipos y prejuicios racistas presentes en la sociedad (Aranda,V., Castro, F., 2008).

De este modo, las comprensiones y referencias que los sujetos efectúan con relación a los objetos sociales, los cuales son explicados, clasificados, jerarquizados y finalmente evaluados, es lo que llamamos una representación social. Para llegar a generarla, el sujeto realiza una 'equivalencia', pero no de forma instantánea, sino que lo hace con referencia a un objeto que se representa cuando está mediado por una figura significada y re-significada. Y es solo en esta condición que emerge la representación y el contenido correspondiente.

Así entendidas, las representaciones sociales son 'filosofías simples' surgidas en el pensamiento social que cobran autonomía. Las personas al nacer y socializarse dentro de un entorno social simbólico las co-construyen y dan por supuesto de manera semejante como lo hacen con su entorno natural y físico. De este modo, el lenguaje, las instituciones

Investigación DIUMCE: Aranda, V. y Castro, F. (2008). Representaciones del imaginario racial en estudiantes de pedagogía. I+I No 11 . DIUMCE, Santiago de Chile.

Investigación DIUMCE: Aranda, V. (2009). De las representaciones xenófobas en estudiantes de pedagogía a una visión intercultural de la educación. 
sociales y las tradiciones forman parte del escenario en que se vive, por tanto ese entorno social simbólico existe para los sujetos como parte de su realidad y como algo que se cuestiona tan solo bajo circunstancias concretas o extraordinarias que se pueden inducir desde la educación y la reflexión crítica. Desde un planteamiento epistemológico educativo acorde, los sujetos se entenderán como agentes de transformación a partir de la conciencia desarrollada. Una vez que éstos comprometen su pensamiento críticamente, los sujetos ya no reproducen ingenuamente su entorno social simbólico y la hipótesis es que el cambio de rumbo colectivo debiera llevarnos al mejoramiento e inclusión armónica de las diversidades. Aprender a convivir con nosotros mismos y 'ayudar a otros a lo mismo, puede constituir un objetivo ambicioso de la educación emocional' y de formar para la interculturalidad y las competencias que ésta requiere (Soriano, 2004).

\subsection{SOBRE RACISMO Y XENOFOBIA}

Por una parte, el racismo es un concepto discutible, pues proviniendo del concepto raza, que se impuso durante el siglo XIX desde una mirada biologicista y que tendió a promover la discrepancia racial y/o supremacía de unos pueblos sobre otros, a partir de diferencias biológicas, que devinieron en las conocidas ideologías y programas políticos del nazismo y fascismo y otros similares del siglo XX. Este calificativo actualmente se refiere a cualquier actitud o manifestación que reconoce o afirma tanto la inferioridad de algunos colectivos étnicos, como la superioridad del colectivo propio. Por otra, la xenofobia es una forma de prejuicio donde la forma de rechazo o aversión se dirige hacia los extranjeros, a cualquier grupo étnico diferente o, incluso, hacia personas cuya fisonomía social, política y cultural es diferente. Se expresa en un juicio a priori, sobre un objeto sin la necesidad de presentar evidencias e incluso, sin llegar a tener una experiencia real o directa hacia esas minorías estigmatizadas.

El racismo se traduce en el rechazo que se manifiesta en diferentes formas de agresividad, violencia simbólica y maltratos hacia las minorías, concentrándose allí donde cohabiten grupos étnicos distintos. En cambio, la xenofobia se basa en el miedo a lo distinto y se expresa en el rechazo y la exclusión integral a cualquier identidad que no sea la propia. Finalmente lleva al sentimiento de odio frente a la diferencia.

La principal distinción entre ambos conceptos es que la xenofobia se centra en el rechazo y la exclusión, mientras el racismo, se plantea sobre un principio de superioridad, ya sea, cultural o racial, de un grupo por sobre otro. Destacamos desde la perspectiva educativa que uno de los rasgos principales de la xenofobia es que impone a cualquier minoría un criterio de asimilacionismo cultural, en pos de preservar la cultura propia. Para esto, recurre a distintos tipos de argumentos -históricos, lingüísticos, culturales, etc-, y de esta forma justifica diferentes formas de exclusión y segregación hacia los grupos étnicos afectados.

Es importante destacar que la xenofobia posee dos caras que llevan al mismo fenómeno, una la del rechazo por parte de la comunidad local frente a la amenaza que representa un importante flujo migratorio hacia el país receptor, y otra el rechazo que los inmigrantes pueden manifestar hacia la cultura que les acoge ${ }^{2}-\mathrm{y}$ que en realidad no

2 Aranda, V. (2004). Modelo de choque cultural y propuesta educativa: una investigación con alumnado latinoamericano de tercer ciclo de la Universidad de Barcelona. Tesis doctoral inédita. 
acoge- llegando a expresar un claro choque hacia la cultura local, no esforzándose por integrarse, ni conocer la cultura, su lengua, ni tradiciones, llegando a generar acciones de repudio hacia la nueva cultura, sea esto resultado del choque cultural que se está vivenciando, frente a la comunidad receptora, o sea por la falta de flexibilidad personal necesaria, ante la necesidad de incorporarse a una cultura distinta de la propia.

Evidentemente, frente a la dinámica de movilización social, que impone la economía global en la que estamos insertos, como resultado de las crisis económicas y la asimetría entre los países desarrollados frente a los que no lo son es que se nos presentan complicados escenarios para el siglo XXI. Desde ya se han incrementado las acciones xenófobas, con distintos niveles de agresión y de bullying en los colegios, partiendo desde acciones individuales hasta colectivas. Frente a lo cual, los medios de comunicación social terminan exaltando y favoreciendo tales manifestaciones, sea minimizando tales acciones o resaltando y/o generalizando cualquier hecho protagonizado por alguien perteneciente a cualquier minoría de inmigrantes.

\subsection{REPRESENTACIONES Y EL SENTIDO COMÚN DE LOS FUTUROS PROFESORES}

Es de este modo que la representación social genera un tipo de conocimiento que surge desde el sentido común, 'porque está socialmente elaborado'. Por tanto, se hace necesario entregar el alcance que se le da a la expresión sentido común, la que está a su vez constituida por 'contenidos cognitivos, afectivos y simbólicos' que tienen un carácter socio-afectivo y que ofrecen orientaciones a las conductas de los sujetos en su quehacer cotidiano, lo que se traduce no solo en organización y comunicación intersubjetiva en sus relaciones, sino en constructos consensuados consciente o inconscientemente en los grupos sociales de los que se participa. Por lo que, comparten con las representaciones un mismo material, ya que se construyen con elementos objetivos y subjetivos, tales como: imágenes, ideas y creencias. Por lo tanto, están saturadas de afectos que condicionan el significado que se tengan, por ejemplo, de estereotipos, prejuicios raciales, o de género, etc., presentes en la sociedad. Todo esto lo encontramos en las historias de vida de los profesores y estudiantes de pedagogía.

Por esta razón es que damos por supuesto que los estudiantes previamente a su elección de estudiar pedagogía, han construido, entre muchas, una serie de representaciones acerca de discriminación, racismo y exclusión, que luego van a acompañar su futuro ejercicio profesional. Estas construcciones probablemente aparecerán en el ejercicio de sus práctica de aula (Aranda,V., 1998, 2005).

Dichas representaciones e imaginario constituyen la base de las prácticas docentes donde este imaginario emerge como sentido común. En este sentido confirmamos que "los docentes enfrentan la práctica educativa equipados con concepciones del mundo físico y social que pertenecen al sentido común, y estas concepciones operan con eficacia simbólica en su práctica profesional, es decir, tienen efectos. Será necesario incluir estas cuestiones a la hora de delinear políticas educativas, discutir y definir desarrollos curriculares, repensar y establecer las diferentes instancias de formación profesional, construir criterios de evaluación, entre otras". (Torrealba, T., 2006: 67).

Visto de esta forma, se hace necesario plantear una propuesta de intervención curricular en la formación docente inicial, que facilite iniciar la reflexión crítica sobre las prácticas pedagógicas cotidianas, para llegar a transformar el punto de vista que 
el estudiante trae en sus representaciones e imaginario y contribuir a deconstruir los prejuicios y estereotipos que esto implica. Para llegar a descubrir desde el desarrollo de la propia conciencia que hay otras formas de abordar las prácticas docentes. Porque si estas concepciones, en tantas construcciones sociales, constituyen una "visión del mundo" que opera de modo eficaz en relación con las representaciones de las que hablamos, es fundamental que se trabajen para comprender el "sentido común" y lograr analizar la problemática que estudiamos.

Se sabe que el maestro es indiscutiblemente uno de los protagonistas centrales en el proceso de escolarización de los alumnos y en las innovaciones que se implementen para mejorar ese proceso y alcanzar un mejor resultado para la educación de nuestro país. Nuestra preocupación se plantea a partir de la importancia que tiene el maestro y su subjetividad. Nuestro objetivo último es delimitar una serie de alcances en torno de los posibles efectos simbólicos de estas representaciones sociales, sus implicancias y la importancia del desarrollo de una conciencia personal sobre dichas representaciones.

La inmersión acrítica del futuro docente en el clima profesional de la escuela, la ausencia de análisis sobre las representaciones, potenciar el desarrollo y proliferación de prácticas uniformes rutinarias y estereotipadas, exigidas, de alguna manera, para la permanencia y reproducción del statu quo de la escuela. Sin el apoyo conceptual y teórico de la investigación sistemática y rigurosa, el proceso de socialización del profesor, a través de las prácticas, fácilmente reproduce los vicios, prejuicios, mitos y obstáculos epistemológicos acumulados en la tradición empírica. (Pérez Gómez, A., 1997).

Entonces, la ausencia de reflexión crítica y de una actitud indagativa frente a las representaciones no permite desvelar los supuestos que subyacen en dichas prácticas o futuras prácticas, estableciéndose así un sistema circular, el cual difícilmente se romperá sin la intervención adecuada; predominará un tipo de pensamiento práctico, experiencial, adquirido en sus respectivos contextos y particularmente en la cultura escolar. En síntesis, tendemos a la reproducción.

Queremos contribuir a la construcción de un modelo educativo que entiende el aprendizaje como un proceso de interacción entre los participantes, un proceso que ayude a reflexionar al sujeto sobre sus ideas y prejuicios, para así modificarlas si se lo considera necesario y estratégico. La autorreflexión y el diálogo entre los participantes del grupo son constantes, de esta forma el sujeto puede hacerse consciente de sus propios condicionamientos, liberarse de determinadas ideas preconcebidas y de concepciones que considera suyas, pero que en realidad responden a unas experiencias y una historia personal condicionadas por la educación, la familia, el Estado, la cultura y la religión.

En nuestra propuesta planteamos que estas representaciones sobre el racismo y la exclusión deben ser estudiadas y resignificadas reflexiva y críticamente desde el inicio de la formación del docente, porque es tan potente el efecto de las representaciones del docente sobre el alumno, especialmente en el caso de familias migrantes en contextos de pobreza que condicionan por medio de estas representaciones y por las interacciones docente-alumno y entre pares, que terminan habilitando una construcción de posibilidades de logro que impactan el rendimiento escolar de los estudiantes; es decir, distinguen entre quienes tendrán éxito o fracasarán en la escuela (Torrealba, T., 2006).

Los profesores en la sala de clases ejecutan actos que ponen de manifiesto el complejo de ideas en el cual basan su práctica educativa, las normas que aceptan, los criterios que adoptan y las decisiones que toman en los ámbitos técnico, teórico y metateórico, 
que conforman dichas prácticas, las cuales no pertenecen a un profesor individualmente, si no que son parte de la cultura escolar y son criterios compartidos por los diferentes actores del sistema educativo. El docente puede ser consciente o inconsciente de todo ello, sin embargo, esta forma de ver y vivir la escuela se va internalizando en toda su historia de inserción en la cultura escolar, tanto en el curriculum manifiesto como en el curriculum oculto y va conformando las pautas de conducta con las cuales asume el rol docente.

En este contexto, el problema desde las representaciones de racismo y exclusión que traen estos profesionales y también los futuros profesores, convoca en la perspectiva de generar nuevas opciones de práctica a partir de un curriculum intercultural orientado a desvelar los fundamentos y principios que subyacen en nuestro imaginario. Se trata de que se instalen nuevas formas de vivenciar el curriculum.

Freire concibió la educación como una práctica de la libertad que se apoya en el uso de un método activo fundado en el diálogo, en la crítica y la formación de conciencia crítica que llevará a las personas a reflexionar sobre su condición social y cultural. "El mejoramiento de la calidad de la educación implica la formación permanente. Se basa en la práctica de analizar la práctica" (Freire, P., 1996: 81). Pues bien, un docente formado con herramientas que le permitan revisar sus propias prácticas estará en condiciones de pararse reflexivamente frente a su quehacer en el aula y esta praxis hoy es cada vez más necesariamente intercultural en Chile, no solamente por la inmigración, sino también por la extrema segregación de las clases sociales en nuestras ciudades y la exclusión en el mismo contexto de los descendientes puro o mestizos de pueblos originarios.

En esta visión, el rol del educador reflexivo consiste en dialogar, tomando casos concretos, y proponer medios con los cuales el sujeto se forma y aprende a hablar de su propio mundo. Esta educación dialógica parte de las experiencias cotidianas de la vida estudiantil. Es una pedagogía situada en lo concreto, en el sentido común y en la vida cotidiana del estudiante. Habla de la inmersión en su propia vida. 'La Educación como práctica de la libertad es un quehacer necesariamente responsable', desde la concepción liberadora e integradora de la pedagogía de Paulo Freire, la cual compartimos.

Desde la intervención curricular propuesta, se espera que el futuro docente tome conciencia de su experiencia de vida y su relación directa con los agentes de socialización escolar y de las teorías curriculares que subyacen en las prácticas docentes, que establecen las representaciones configuradas como paradigma educativo dominante, y se espera promover una aceptación conciente de las nuevas competencias con las cuales el futuro docente debe asumir los cambios que se impulsan en la Reforma Educacional del país.

\section{LA NECESARIA EDUCACIÓN INTERCULTURAL}

¿Cómo promover un currículum intercultural para la FID? Las políticas actuales del Ministerio de Educación que promueven la transversalidad e integración (La persona y su entorno, Mineduc, 2003) son restrictivas e incluso ambiguas para responder esta pregunta. La restricción principal es la visión de la multiculturalidad en la acción docente, la que implica considerar solo una visión de diversidad cultural a partir de una cultura hegemónica que acoge y/o asimila y/o subsume a otra cultura de menor influencia. Por ello y frente a la carencia de una política docente que promueva el avance a la interculturalidad, se 
plantea un desafío no solo en reemplazar la postura de multiculturalidad, sino al mismo tiempo diseñar alguna política de interculturalidad donde los docentes se formen, para enseñar en los próximos años con herramientas concretas en los temas ligados a la diversidad cultural.

La interculturalidad encuentra un nicho natural en el paradigma curricular denominado Modelo Pedagógico Post-crítico que considera, por un lado, que los ideales del respeto por la diversidad cultural están vivos, pero aún falta mucho por conseguir en las distintas sociedades en progresivo cambio. Por otro lado, dada la complejidad de la diversidad cultural actual, sólo es posible resignificar y reconstruir las categorías con que hoy se comprenden desde la interculturalidad (Da Silva, T., 2001). Asimismo, se propone un Curriculum Interdisciplinario porque la complejidad de la problemática requiere del aporte que puedan ofrecer las distintas disciplinas sociales: antropología, filosofía, psicología social y sociología, y las nuevas síntesis aportadas desde el curriculum.

Se busca promover un paradigma que potencie interculturalidad, que potencie estrategias de trabajo capaces de tomar en cuenta la diversidad, con sus riquezas, pobrezas y sus complejidades. En esta etapa de estudio, los conceptos de cooperación y diálogo en educación son básicos para avanzar hacia una mejora en las complejas interacciones humanas.

¿Cómo considera el curriculum oficial (planes y programas de estudio) el tema de la interculturalidad? Lo más cercano dice relación con la promoción de los Objetivos Fundamentales Transversales, los que se definen como aquellos objetivos que tienen un carácter comprensivo y transversal, cuyo logro se funda en el trabajo formativo del conjunto del currículum. Se los ha identificado como aquellos que apuntan a las finalidades generales de la enseñanza (MINEDUC, 1998).

Ubicar la educación intercultural ligada a la transversalidad está dado porque es el espacio que aborda temas como el género, la moral, la educación para la paz, entre otros. Los más recurridos para desarrollar la promoción de la educación intercultural son los temas relacionados con la paz y la interculturalidad propiamente tal. Los que se definen como:

Educación para la paz: construir una paz positiva ligada a la justicia y la igualdad, fomentando el diálogo como fuente de resolución de conflictos y la valoración y respeto por la diversidad cultural.

Educación intercultural: como un enfoque educativo que se dirige a todos y cada uno de los miembros de la unidad educativa y de la sociedad. No se orienta a realizar acciones específicas con grupos específicos. Su objetivo es el cambio de la escuela y del curriculum ordinario de forma que se logre una real igualdad de oportunidades educativas para todos los estudiantes. El éxito escolar se define en términos de lograr objetivos académicos valiosos, tanto en cuanto el desarrollo de competencias y habilidades para la vida como en el de la adquisición de competencias comunicativas en contextos multiculturales (DíazAguado, M.J., 2007).

Frente a estos temas el MINEDUC (2002) ha planteado los siguientes desafíos:

- El desarrollo integral de los pueblos indígenas, en términos de sostenibilidad y sustentabilidad, así como de identidad y educación y cultura.

- La construcción de la multiculturalidad, en términos de la aceptación e inclusión de los pueblos indígenas en la sociedad chilena. 
- Las relaciones entre pueblos, comunidades y personas, en términos de asumir la no discriminación y el rechazo a toda forma de racismo.

- Una mirada con perspectiva histórica, en términos de establecer un Pacto Social por la Multiculturalidad al que concurran todos los actores en un compromiso de largo plazo.

La educación y la socialización tienen como función esencial configurar disposiciones psíquicas, ideológicas y de acción social acordes con el programa cultural que tiene cada sociedad, que deberá ser aprendida por niños y jóvenes en la educación formal y familiar, los grupos de pares e informalidad y los medios de comunicación. De acuerdo con esta idea, cabe destacar que la Educación Intercultural busca el enriquecimiento mutuo entre grupos humanos diversos y el reconocimiento y valoración de la diversidad cultural en la sociedad y en especial en la escuela. Se desprende que los propósitos centrales de la Educación Intercultural es instalar en la población escolar competencias interculturales que les permitan interactuar de manera horizontal con personas pertenecientes a grupos humanos diversos (étnicos, culturales y sociales) concernientes al ámbito de las actitudes positivas frente a la diversidad cultural que se expresa en la sociedad, a las habilidades comunicativas y las habilidades cognitivas que facilitan la comprensión y valoración del contacto entre las culturas.

La Educación Intercultural tiene dos parámetros esenciales. El primero hace referencia a la construcción del currículum escolar, destacándose los proyectos educativos institucionales y los proyectos institucionales curriculares; la generación de un currículum crítico y el reconocimiento de tiempo y espacio para las minorías (étnicas, culturales, sociales). El segundo parámetro dice relación con los profesores y profesoras y el quehacer pedagógico intercultural al interior de la sala de clases. En este marco, se releva la necesidad de formación de los estudiantes de pedagogías en educación intercultural y de disposiciones legales que amparen y defiendan a las minorías; y un modelo pedagógico que se funde en la interculturalidad como eje vertebral de las nuevas relaciones sociales que experimenta la sociedad chilena, derivadas de la globalización y la masificación de las comunicaciones.

Desde la perspectiva de la problemática que experimenta la Educación Intercultural se destacan dos nudos críticos. El primero consiste en el carácter axiológico de la Educación Intercultural, pues tiene un valor inherente y comparado el estudio de diferentes culturas en que se genera la oscilación de un péndulo entre el etnocentrismo y el relativismo cultural. En efecto, ambos extremos por sí mismos no contribuyen al tratamiento adecuado del foco de estudio de la Educación Intercultural. Por otra parte, la autenticidad de la Educación Intercultural constituye el segundo nudo crítico de ésta y se refiere a que educar a un niño o niña en diversas formas de vida cultural constituye una enorme tensión respecto de los capitales sociales y culturales de origen versus los que las sociedad de acogida exige, y la lengua se puede constituir en el primer obstáculo.

En estos contextos de diversidades y tensiones crecientes, la escuela debe atender los asuntos de grupos minoritarios y evitar, o mitigar, connotaciones de violencia simbólica y física. Esta problemática tiene dimensiones pedagógicas, políticas, económicas y culturales para la convivencia democrática en una sociedad que reconozca y valore la interculturalidad como modo de vida. La interculturalidad pone a la educación como pilar fundamental para el desarrollo de esta práctica democrática, debido a que la educación 
históricamente se ha caracterizado por su "tendencia homogeneizadora y funcional al sistema político y económico sustentado en una estructura de diferenciación y desigualdad social" (Díaz, M., 2004: 192).

Son diversas las medidas que han tomado los sistemas educativos para enfrentar la diversidad cultural. Estas se han clasificado en tres tipos: tecnicista, moral y sociopolítica (Torres, J., 1996).

- Perspectiva tecnicista: Aquí se destaca la importancia de la igualdad de oportunidades y de desarrollar medidas compensatorias para solventar los problemas de bajo rendimiento académico. Para llevar a cabo esto se recurrirá a especialistas o expertos.

- La respuesta moral: Se proponen pedagogías que apunten al conocimiento personal de cada estudiante. A medida que se conozcan mejor, irán desapareciendo conductas racistas y discriminatorias.

- Solución socio-política: Se centra en destacar la necesidad de justicia dentro de una sociedad plural. Para esto se demuestran diferentes perspectivas e interpretaciones de los contenidos curriculares, alzando una crítica hacia los contenidos tradicionales de "conocimiento legítimo", demostrando que aquel conocimiento ha sido utilizado para satisfacer las necesidades de los grupos que detentan el poder y para oprimir y marginar a los grupos étnicos.

Es este sentido, es de suma importancia plantearnos la educación intercultural desde enfoques sociopolíticos, donde se permita construir la historia a favor de las clases y etnias más oprimidas, con "currículum destinados a facilitar una reconstrucción social y una emancipación cultural sobre la base de una valoración positiva de las culturas minoritarias" (Torres, J., 1996: 174), apuntando a que todas las personas que asistan a un centro educacional se sientan orgullosas de su etnia o procedencia, promoviendo el acercamiento, el diálogo y el respeto mutuo entre personas.

Sin embargo, se debe tener cuidado con enfoques que tienden a tergiversar el objetivo real de la educación intercultural, porque lo importante no es la diferencia cultural sino el otro diferente a mí "...lo intercultural se ha pretendido ver solo y exclusivamente como la defensa y promoción de la diferencia, como un derecho inalienable de preservar la identidad de cada cultura minoritaria frente a la influencia de las culturas hegemónicas. Esta actitud ha llegado a convertirse en algo contraproducente a la idea misma de interculturalidad” (Minguez, R., 2007: 27). También se debe rechazar todo tipo de perspectiva instrumentalistas o economicistas que reducen la condición de los inmigrantes a meros objetos mercantiles sustentadores de economías basadas en la explotación.

Hablar de educación intercultural no se reduce solamente al conocimiento profundo de la cultura del otro diferente, sino que se refiere más bien a la importancia de las relaciones, “...la educación intercultural no pretende solo la comprensión de la cultura, el respeto a sus convicciones y modos de vida, sino también el reconocimiento de mi responsabilidad hacia el que me demanda una respuesta de acogida, entonces dicha educación se traduce necesariamente en una educación moral” (Minguez, R., 2007: 37). Porque al hablar de educación lo primero que pensamos es en la educación de saberes y contenidos de este estudiante inmigrado, pero en realidad lo que importa es su acogida y ésta debe estar basada en una acción ética donde la palabra clave es hospitalidad, lo 
que implica que el educador debe ser siempre responsable del otro inmigrado. La responsabilidad, el diálogo y el cuidado hacia aquel que solicita ayuda y atención, que nos necesita, es un valor primordial en educación intercultural. No obstante, mantener esta postura asimétrica implica sustentar paternalismo, pues el emigrado también debe intentar adaptarse a las nuevas condiciones en el contexto de acogida brindado; y si esto no es visto por ellos debe, pedagógicamente, ser mostrado.

Actualmente, se ha llegado a creer erróneamente que la escuela intercultural solo debe construirse desde contextos con diversidad cultural explícita, es decir, centros educativos con estudiantes provenientes de pueblos aborígenes o de familias inmigradas. Pero los otros diferentes no sólo provienen de contextos externos, también son producidos por las contradicciones socioculturales de nuestras propias sociedades, como es el caso de las subculturas (flaites, sectores dominados por el narcotráfico, etc.), que nos imponen nuevos desafíos para educar en la diversidad, el respeto y la solidaridad.

La escuela intercultural y su organización deben partir necesariamente desde un espíritu innovador y crítico del actual modelo de educación cerrado. Es decir, debe comenzar por una transformación partiendo por la democratización de los espacios de discusión y toma de decisiones, contemplando todos los aspectos referidos a Derechos Humanos.

Cuando se trata de decidir cuál es el futuro de la escuela, los estudiantes, padres, madres, profesores y profesoras deben tener una voz prioritaria, con un modelo a construir. Además, la escuela debe abrir sus puertas, cerradas hacia la comunidad, el barrio etc., e involucrarse activamente en su vida y cultura.

Lo más importante y que le da consistencia, permanencia y proyección a este proceso democrático son las prácticas pedagógicas innovadoras, las cuales deben estar siempre dirigidas hacia este objetivo. En este sentido, los profesores y directivos tienen un papel predominante. El principal sujeto impulsor de cambios educativos es el profesorado consciente de sus contextos, limitaciones y posibilidades, a través de prácticas reflexivas y liberalizadoras. En el tratamiento didáctico de la interculturalidad es de suma importancia que los maestros y maestras y también los estudiantes de pedagogías trabajen por la erradicación de estereotipos y prejuicios propios de la sociedad que se han instalado en la mentalidad de sus alumnos y alumnas, para lo cual el mismo profesorado debe comenzar por modificar sus visiones de mundo y sus conductas que estén permeadas por influencias racistas o xenófoba.

Después de lo expuesto, lo lógico sería que con prontitud estos sean temas que formen parte de un curriculum formal en la formación inicial docente. Ofrecer alternativas en dicha formación es lo que permitirá la superación de sesgos de exclusión, y de esta forma contribuir a formar ciudadanía plural. En este proceso de formación, desde esta nueva mirada, se espera que el estudiante tome conciencia de su experiencia de vida y su relación directa con los agentes de socialización escolar y de las teorías interculturales que subyacen en las prácticas docentes.

\section{3. ¿CÓMO LO HEMOS HECHO?}

En nuestro caso, hemos desarrollado cursos-talleres en la modalidad mixta con procesos formativos presenciales y virtuales, de acompañamiento y reconstrucción conceptual colectivo e individual, en base a tres ejes temáticos: 
- Representaciones sobre rol docente

- Multiculturalidad e interculturalidad y globalización

- Educación intercultural

Es a partir de esta metodología mixta: Presencial y semipresencial de seminarios y foros on-line en donde se van trabajando las representaciones configuradas como paradigma educativo dominante, y se espera promover una aceptación conciente de las nuevas competencias con las cuales el futuro docente debe asumir los cambios que se impulsan en la Reforma Educacional del país.

Por una parte, intentaremos modificar el ser a partir de cambiar el hacer. Para ello hemos posibilitado que los procesos emerjan en su forma más genuina, a través de abrirnos al diálogo con el otro y con nosotros mismos, para construir redes de interrelaciones no jerarquizadas en las que cada uno se constituye en mediador para el otro, proporcionándole un acompañamiento permanente (on-line) y que toma en cuenta los tiempos de cada uno, propiciando espacios no homogéneos de aprendizaje, por la necesidad formativa y creadora de hacer fluir la voz del otro desde su propia realidad. Por otra, pretendemos alejarnos del uso instrumental y mecánico de las herramientas informáticas, para centrarnos en aquellos atributos que permiten diseñar espacios de construcción de conocimiento, donde el aprendizaje se constituye en un proceso dinámico y de colaboración recíproca entre todos los protagonistas del acto educativo.

El proceso recién descrito facilitó responder a nuestra inquietud con esta propuesta, reconociendo la educación como un proceso potencial de transformación y de cambio para mejorar nuestra realidad.

Las categorías levantadas a partir de nuestro trabajo son cuatro, las tres últimas transversales, ya que aparecen en forma recurrente en casi todas las intervenciones de los participantes de los foros.

- Relaciones subjetivas e intersubjetivas entre los sujetos participantes.

- Intervenciones recíprocas de acuerdo a las diferentes fuerzas de las voces de los sujetos.

- El sujeto se desenvuelve sistémicamente, no separando su razón, emoción, intuición y experiencias.

- Son intervenciones que generan movimiento y provocan cambios, inflexiones y reflexiones.

El espacio es un todo sistémico en red, colaboración recíproca para el conocer y el aprender. Para concluir, el proceso recién descrito permite desde la investigación educativa, contribuir y responder inicialmente a un proceso potencial de transformación y de cambio para mejorar nuestra realidad educativa desde la perspectiva de la inclusión social.

\section{COMENTARIOS FINALES}

En el contexto del Bicentenario de la Independencia de nuestro país se busca preparar condiciones sociales, educacionales y económicas que permitan a la población alcanzar niveles de vida de calidad, en consonancia con los procesos de internacionalización que 
requiere un mundo plural, que, a su vez, demanda nuevas competencias, como la comunicación intercultural, que no surge espontáneamente, sino que hay que desarrollarla.

Ante tal escenario, llegamos a las siguientes conclusiones:

- Es fundamental una intervención curricular en la formación docente inicial que permita iniciar la reflexión crítica sobre temas que hoy no pueden estar ausentes del curriculum de dicha formación: El análisis de las prácticas pedagógicas cotidianas, temáticas de Educación Intercultural, DD.HH., la historia de la exclusión en Chile, etnias, género, grupos políticos y otras, para poder transformar la visión que el estudiante trae desde sus propias representaciones sociales, en su imaginario, y contribuir a deconstruir los viejos esquemas y modelos que esto implica. Estimamos que la propuesta curricular de la formación inicial no puede ignorar la existencia de dichas representaciones y debe actuar sobre ellas, pues las concepciones y preconcepciones que sustentan las prácticas pedagógicas no pertenecen a un profesor individualmente, son parte de la cultura en general y de la cultura escolar en particular, las que son compartidas por diferentes actores del sistema educativo, como parte del sentido común no reflexionado ni superado.

- El papel que desempeñan las representaciones con relación a la xenofobia es crucial; argumentándose una supuesta identidad en peligro, van instituyendo fenómenos de exclusión social, lo que a la larga pone en riesgo a una comunidad completa, en la medida que no desarrollamos procesos de inclusión, reflexión, flexibilidad y nuevas competencias hacia una cultura intercultural, que nos permita valorar los aportes que implica la interacción con otras culturas, potenciando la mutua integración en un mundo globalizado.

- Dado el contexto que nos marca la globalización del mercado, la que posee un rol predominante en los procesos migratorios modernos, y puesto que en ningún periodo anterior existió tanto desplazamiento, éste es uno de los efectos más visibles del fenómeno globalizador. Ésta es una ideología que se basa en una economía capitalista neoliberal, que se esmera por intensificar las intercomunicaciones, difundir información con rapidez, producir conocimientos y servicios e imponer un pensamiento único a nivel global, es decir, uniformar los estilos de vida, rompiendo con la diversidad étnica y cultural, profundizando las desigualdades sociales, lo que obliga a que algún sector atienda estas consecuencias, y en este caso es el sector educativo el llamado a hacerse cargo.

\section{REFERENCIAS BIBLIOGRÁFICAS}

Arnaíz, P. (2004). Respuesta a la diversidad desde una propuesta intercultural. En Soriano, E. (Ed.). La práctica educativa intercultural. Madrid: La Muralla S.A.

Aranda, V. y Castro, F. (2008). Representaciones del imaginario racial en estudiantes de pedagogía. I+I N ${ }^{\circ} 11$. Santiago de Chile: DIUMCE.

Aranda, V. (2004). Modelo de choque cultural y propuesta educativa: una investigación con alumnado latinoamericano de tercer ciclo de la Universidad de Barcelona. Barcelona (Tesis doctoral inédita).

Araya, S. (2002). Las representaciones sociales: ejes teóricos para su discusión. Costa Rica: FLACSO. 
Cañulef, E. (1998). Introducción a la educación intercultural bilingüe. Pillán. Temuco.

Castles, S. (2002). Globalización y migración: algunas contradicciones urgentes. www.griescas.org. Díaz, M.J. (2007). Educación Intercultural y aprendizaje cooperativo. Madrid: Pirámide.

Da Silva Tomaz Tadeo (2001). Espacios de identidad. Octaedreo: México.

Freire, P. (1996). Política y Educación. Madrid. Siglo XXI Editores.

Minguez, R. (2007). La educación intercultural como respuesta ético- moral. En Castillo, A., Quevedo, N. y Zúñiga, J. (1999). Palabras Mestizas: el discurso de la prensa chilena frente a la actual inmigración peruana, tesis para obtener título de grado, Escuela de Periodismo, Universidad de Santiago de Chile, Santiago.

Pérez Gómez, A. (1997). Socialización Profesional del Futuro Docente en la Cultura de la Institución Escolar. El Mito de las Prácticas. Universidad de Zaragoza. Revista Universitaria de Formación del Profesorado. $\mathrm{N}^{\circ} 29$.

Singer, P. (2003). Un solo mundo. La ética de la globalización. Editorial Paidós. Barcelona. España.

Stefoni, E., C. (2003). Inmigración peruana en Chile. Una oportunidad a la integración. Santiago de Chile: Universitaria.

Soriano, E. (2004). Identidad y Ciudadanía: dos retos de la práctica educativa Intercultural. En Soriano, E. (Ed.). La práctica educativa intercultural. Madrid: La Muralla S.A.

Torres, J. (1996). El currículum oculto. Madrid: Morata.

Torrealba, T. (2006). El sentido común de los maestros: algunos problemas epistemológicos. Revista mexicana de Investigación Educativa $\mathrm{N}^{\circ}$ 16, Vol. 7. México.

Ramonet, I. (1999). La Globalización. www.unesco.org/issi/rics160/title pagee160html RIC, Revista Internacional de Ciencias Sociales. $\mathrm{N}^{\mathrm{o}} 160$.

ONU (1999). Informe del Relator Especial sobre las formas contemporáneas de racismo, discriminación racial, xenofobia y formas conexas de intolerancia, Washington, E/CN.4/1999/15. 